\title{
If you pick up the children, I'll do the groceries: spatial differences in between-partner interactions in out-of-home household activities
}

\author{
Tim Schwanen, Dick Ettema \\ Faculty of Geosciences, Utrecht University, PO Box 80115, 3508 TC Utrecht, The Netherlands; \\ e-mail: t.schwanen@geog.uu.nl, d.ettema@geog.uu.nl
}

\section{Harry Timmermans}

Urban Planning Group, Faculty of Architecture, Building and Planning, Eindhoven University of Technology, PO Box 513, 5600 MB Eindhoven, The Netherlands;

e-mail: h.j.p.timmermans@bwk.tue.nl

Received 28 November 2005; in revised form 16 February 2006

\begin{abstract}
While many studies have been conducted about the allocation of household duties within households, little is known about the impact of land use and accessibility on the distribution of out-ofhome household tasks between spouses and about men's participation in such activities. This paper addresses this impact, while controlling for the impact of household structure, life cycle, employment status and hours, access to transport systems, and interactions among activities in persons' activity schedules. Path models for male - female couples in the Amsterdam-Utrecht corridor, the Netherlands, show that land use and accessibility influence between-partner interactions in maintenance activity participation, although their role appears to be smaller than that of sociodemographics and access to transport systems. While women perform the bulk of out-of-home household tasks, men are responsible for a larger share of out-of-home household duties in neighbourhoods characterised by a higher population density and/or more diversity of land uses than they are in lower density and/or less diverse neighbourhoods. However, women's responsibilities are not reduced to the same extent, because spouses' joint participation is also somewhat larger in higher density, more diverse neighbourhoods and because part of men's participation in these neighbourhoods reflects household activities not undertaken elsewhere.
\end{abstract}

\section{Introduction}

Who does which household tasks is an issue that has concerned sociologists, economists, geographers, and transport researchers for several decades now. Emancipation processes and economic restructuring have raised the issue of whether a gendered responsibility for domestic labour will persist. Empirical evidence suggests that women, irrespective of their employment status, continue to carry prime responsibility for these tasks (Hanson and Pratt, 1995; Morris, 1990; Pinch and Storey, 1992; Presser, 2003). There are, nonetheless, various factors affecting men's and women's responsibility for household tasks. In addition to the impact of class, occupation, and life cycle, sociologists have considered the relevance of gender roles and power differentials among spouses (Morris, 1990). Thus, men conduct more domestic tasks if spouses' role orientations are more egalitarian (Huber and Spitze, 1983; Presser, 1994), and women's resources relative to men's are developed more strongly (Antill and Cotton, 1988; Presser, 1994). Other factors that have received much attention in previous research are employment status and schedules (Presser, 2003). Some studies found that men take over more inhome and out-of-home tasks as women work longer hours (Ettema et al, 2007), while others concluded that women's working hours have significant ramifications for their daily lives but far less for their partners' daily activity-travel patterns (Hanson and Hanson, 1981; Pinch and Storey, 1992). 
Given the abundance of work on the household division of labour, we believe that the current paper makes a threefold contribution to the existing body of knowledge. Firstly, while there has been much attention on the impact of temporal factors, such as the number of hours worked and the timing of work activities, the spatial differences in the gender division of labour have attracted less attention. Where sociologists tend to ignore such differences, feminist geographers have studied how women and men coordinate their everyday activities in space and time. They have shown convincingly that women are able to combine work and domestic duties through working close to home, chaining trips into complex journeys, driving cars, and relying on social networks (Dowling, 2000; Hanson and Pratt, 1995; Kwan, 1999). To the best of our knowledge, though, studies in this tradition have not provided systematic insight into the impact of accessibility to shops, services, and other facilities on the distribution of out-of-home tasks between spouses. We consider this unfortunate in the light of timegeographical research that has shown how location factors such as the accessibility of jobs and services affect time allocation and activity-travel patterns (Burns, 1979; Kwan and Weber, 2003).

Secondly, previous research has shown little appreciation for the possibility that spouses conduct household tasks together. The question of who does which household tasks is usually studied from an 'either-or' perspective; the 'and' option is often overlooked. Neglecting joint activity participation may, however, result in erroneous conclusions about the impact of men's engagement in domestic tasks on women's activity patterns (and vice versa). If men take care of more out-of-home household activities but conduct many of these together with their wives, women's responsibilities for, and time devoted to, such tasks will not be reduced much.

Thirdly, much of the geographical literature on the gender division of labour employs data from Anglo-Saxon countries. Given that gender relations are culturally and geographically contingent (Massey, 1995), studies from countries like the Netherlands can provide further insights into gender differences in activity patterns. Collective welfare provisions in the Netherlands are more generous than in the liberal welfare states of the UK and USA but not as extensive as in the social-democratic welfare states of the Nordic countries (Esping-Andersen, 1999). In addition, Dutch policy discourses emphasise mothers' role as primary carers for children (Knijn, 2004). Consequently, female labour-market participation is relatively low and employed women mostly work part-time. In the period $1992-2004$, the share of single-worker couples dropped from $50 \%$ to $27 \%$, while that of couples with one full-time ( $>35$ hours) and one (female) part-time job rose from $27 \%$ to $41 \%$. In 2004 less than $15 \%$ of couples combined two full-time jobs, and this percentage was below $10 \%$ for households with children younger than 12 years (Van der Valk, 2005).

In summary, using data from the Netherlands, this paper explores the impact of location factors, such as accessibility to shops and other facilities and land-use diversity, on the distribution of out-of-home household tasks between spouses and on men's participation in such activities, while controlling for the influence of sociodemographic factors, access to transport systems, and interactions among activities in persons' activity schedules. Decisions regarding working hours, which will strongly affect the participation in out-of-home household activities, are treated as given in this study. We also consider whether these household tasks are undertaken individually or jointly, in order to avoid erroneous conclusions about men's and women's contribution to out-of-home domestic labour. Out-of-home household tasks include chauffeuring, grocery shopping, personal business, and shopping for convenience goods. Both the total frequency of the out-of-home household activity episodes and the number of episodes in each of these categories are considered in the empirical analysis. Path analysis is employed to capture the 
interdependencies between men's, women's, and joint participation in household activities. Activity diary data are used that have been collected in the Amsterdam - Utrecht corridor, the Netherlands, for the AMADEUS project (see section 3; Timmermans et al, 1998).

\section{Theory and hypotheses}

In this study we assume that individuals engage in daily activities because they need and wish to pursue a set of individual and household-level goals, including physical well-being, self-actualisation, and child care. For this, they have to organise how, where, and when they interact with other humans and instruments. Various types of constraints play an important role in this process as they restrict and enable activity participation (Arentze and Timmermans, 2000; Hägerstrand, 1970): (i) capability constraints or physiological, cognitive, and instrumental restrictions (eg a minimum time required for sleeping and the maximum attainable travel speed); (ii) authority constraints or rules, laws, and norms, including gender role orientations and store hours. In the Netherlands, supermarkets tend to be open until 8 PM or $10 \mathrm{PM}$ on weekdays, but other shops normally close at 6 PM except for one evening per weektypically Thursdays or Fridays - when they are allowed to close at 9 PM. On Saturdays, shops close at 5 PM or 6 PM; on Sundays, they are normally closed (excepting those in the centres of such major cities as Amsterdam); (iii) intrapersonal coupling constraints, because activities require individuals to be at a certain location for a certain time period, which restricts the time available for other activities; (iv) interpersonal coupling constraints, reflecting that activities often need to be coordinated with others; (v) monetary budget constraints; (vi) availability of transport modes, such as a private car and public transport; and (vii) characteristics of the built environment, such as the density, locations, and accessibility of functions.

Given a set of longer term choices with respect to residential location, labour-force participation, and access to transport systems (car ownership and public transport cards), individuals and households can cope with these constraints in various ways on a daily basis. Consider, for instance, the coupling constraints associated with working hours. If a spouse works longer hours, he or she has less time for domestic tasks. Relegating household activities to one's partner may then be a reasonable strategy, as well as an overall reduction in household tasks at the household level (Morris, 1990; Presser, 1994). Such effects may, however, not be gender neutral. Previous work has suggested that males' role does not increase much if women work longer hours (Hanson and Hanson, 1981; Pinch and Storey, 1992). The coupling constraints associated with the presence of young children and household size may also have gender-specific consequences. While men may conduct more tasks in larger households and/or in couples with young children than in smaller and/or childless households, the differences may be more pronounced for women. This strategy of task specialisation may reflect a joint attempt by the spouses to increase the efficiency of the household activity schedule (Gliebe and Koppelman, 2002) but may also be, especially in the Netherlands, a reaction that complies with the prevailing moral climate and gender ideology (Knijn, 2004).

The impact of location factors such as accessibility to shops, services, and other facilities and of population density on the distribution of out-of-home activities may also differ for men and women. There is some evidence that better accessibility stimulates out-of-home activity participation and trip making (Boarnet and Crane, 2001; Ettema et al, 2007), but such effects may, at least for domestic tasks, be gender specific. One way for couples to cope with poor accessibility to facilities is to assign out-ofhome household tasks to one spouse-usually the female-who can, for instance, combine several tasks in multistop activity chains. Gender-specific role specialisation may thus be a sensible response to constraints imposed by the built environment. 
If, however, accessibility is better, men may take care of more household tasks, because such tasks tend to involve less effort in neighbourhoods with better access to shops, services, and other facilities. These tasks can be included more easily in the overall activity schedules of men living there because travel times are shorter and there are more opportunities to combine household tasks with other activities (Ettema et al, 2007; Hanson, 1982).

Implicit in these arguments is the notion that men's participation in out-of-home household tasks may be more sensitive to location factors than women's participation is. This may reflect that men's engagement in household activities is more discretionary than that of women. Kwan (1999; 2000), for instance, has shown that women's household activities tend to be more fixed in space and time than those of men, and Aitken (2000), drawing on interview data, argued that fathers responsible for child care felt they were merely 'helping out' their spouses, who were still considered the primary carers. However, the literature also suggests that types of household activities differ in terms of their space-time fixity. Chauffeuring trips tend to be more fixed in space and time than other activities (Kitamura, 1983; Misra and Bhat, 2001). It is therefore also important to look at different types of activities when analysing the impact of location factors (and other variables) on the division of out-of-home household activities. We may, nonetheless, hypothesise that, in general, in higher density neighbourhoods providing good access to shops and other facilities men undertake more out-of-home household activities.

One would expect males' larger responsibility for out-of-home household activities in neighbourhoods providing better access to facilities to reduce the participation of women in these activities and the complexity of the daily activity patterns of women. If, however, men in such locations are more inclined to accompany their partners, the demands on women will not be smaller. It is therefore important to distinguish between men's solo, women's solo, and spouses' joint activity participation, as recent work in activity-based travel demand analysis has suggested (Bhat and Pendyala, 2005). Location factors may also affect the choice to participate in an activity jointly or independently, although this effect may depend on whether spouses undertake activity together for reasons of efficiency, altruism, or companionship (Gliebe and Koppelman, 2002).

Two arguments about the impact of location factors on joint activities for efficiency reasons can be put forward. A negative association between accessibility and joint activity participation may exist. Because individuals in locations providing poor accessibility to facilities may experience more limited opportunities for activity participation, spouses can pool resources and combine multiple, individual demands for goods and services into one joint trip and so increase the efficiency of the household activity pattern (Ettema et al, 2007; Gliebe and Koppelman, 2002). However, because spouses' activity schedules need to be synchronised, joint activities also entail coordination costs, which can make joint participation less efficient than solo activities - in particular, when spouses experience many coupling constraints (Gliebe and Koppelman, 2002; Srinivasan and Bhat, 2005). Coordination costs may also make joint participation less efficient if access to potential destinations is better and individuals can engage in solo activities more easily. Thus, if households live in high-density, mixed-use neighbourhoods, we may expect more solo activities (Ettema et al, 2006).

Efficiency considerations are not the only factors at play in decisions about joint activity participation. Spouses can also engage in joint out-of-home household activities to help one another or simply to be together - that is, for reasons of altruism or companionship (Gliebe and Koppelman, 2002). This means that we may also expect spouses in neighbourhoods providing good access to shops and other facilities to 
engage in joint participation relatively often. Altruism and companionship may, for instance, be especially relevant for dual-earner households with both partners working long hours and/or child care taking much time. They may also matter more to specific types of out-of-home household tasks. Altruism may be more relevant for chauffeuring activities (eg to reduce one's partner's fear of driving in the dark) and grocery shopping (eg to carry grocery items); companionship may be more relevant for shopping for convenience goods, which can be less task oriented and undertaken for experiencing the shopping activity itself $(\mathrm{Ng}, 2003)$. In contrast, efficiency motivations may be particularly relevant for grocery shopping and personal business activities (eg visits to a post office, bank, library, etc), which are principally undertaken to obtain goods or acquire services.

To summarise, we expect that women will be responsible for the majority of out-ofhome household tasks in households facing many space - time constraints. If constraints are less binding - for instance, because households live in neighbourhoods providing good access to shops and other facilities - men may take care of more household tasks. Whether this reduces women's responsibilities for such chores depends on the mode of the activity participation. If the increased role of men is due to more joint participation, which may be influenced by location factors in various ways, women's overall responsibility for household activities will not be reduced. When analysing how location factors affect households' organisation of out-of-home household activities, we will also address the impact of household structure, life cycle, employment status and hours, and access to transport systems because these have autonomous effects on activity participation (Axhausen et al, 2001; Hanson, 1982; Pas, 1984) and distinguish different types of out-of-home household activities.

\section{Research design}

\subsection{Data}

The AMADEUS survey comprised two-day activity diaries, collected in the Amsterdam Utrecht corridor in 2000-01. This corridor coincides more or less with the North Wing of the Randstad and comprises the polycentric daily urban systems of Amsterdam and Utrecht, which have become increasingly interdependent in functional terms over the past decades and nowadays include various major activity or employment concentrations in addition to the city centres of Amsterdam and Utrecht (figure 1). Within the North Wing, fifty-seven neighbourhoods as defined by Statistics Netherlands were selected which varied in terms of building density (hyper, high, medium, low); distance to the Amsterdam and Utrecht city centres (low, medium, high); and private car and public transport orientation (car oriented, transit oriented, car and transit oriented). These criteria reflect the aims of the AMADEUS program, which concentrated on the impact of multimodal transport systems on activity - travel patterns (Timmermans et al, 1998). In addition, neighbourhoods were targeted with an overrepresentation of higher income households and family households. These choices resulted in an oversampling of public transport users and a somewhat smaller variation in sociodemographics than for the North Wing population at large (Krygsman, 2004). Land-use data on the four-digit postal code level were added to the activity diary information. Four-digit postal code areas do not necessarily overlap with the definitions of neighbourhoods of Statistics Netherlands; they tend to be larger. The postal code data were used, however, because much land-use information is not available at the neighbourhood level. In terms of land use, the postal code zones in which the fifty-seven neighbourhoods are located have average population and employment densities of 42.6 persons/ha $(\mathrm{SD}=37.7)$ and $19.1 \mathrm{jobs} / \mathrm{ha}(\mathrm{SD}=32.3)$, respectively. Their average size is 229.4 ha $(\mathrm{SD}=246.4)$. 


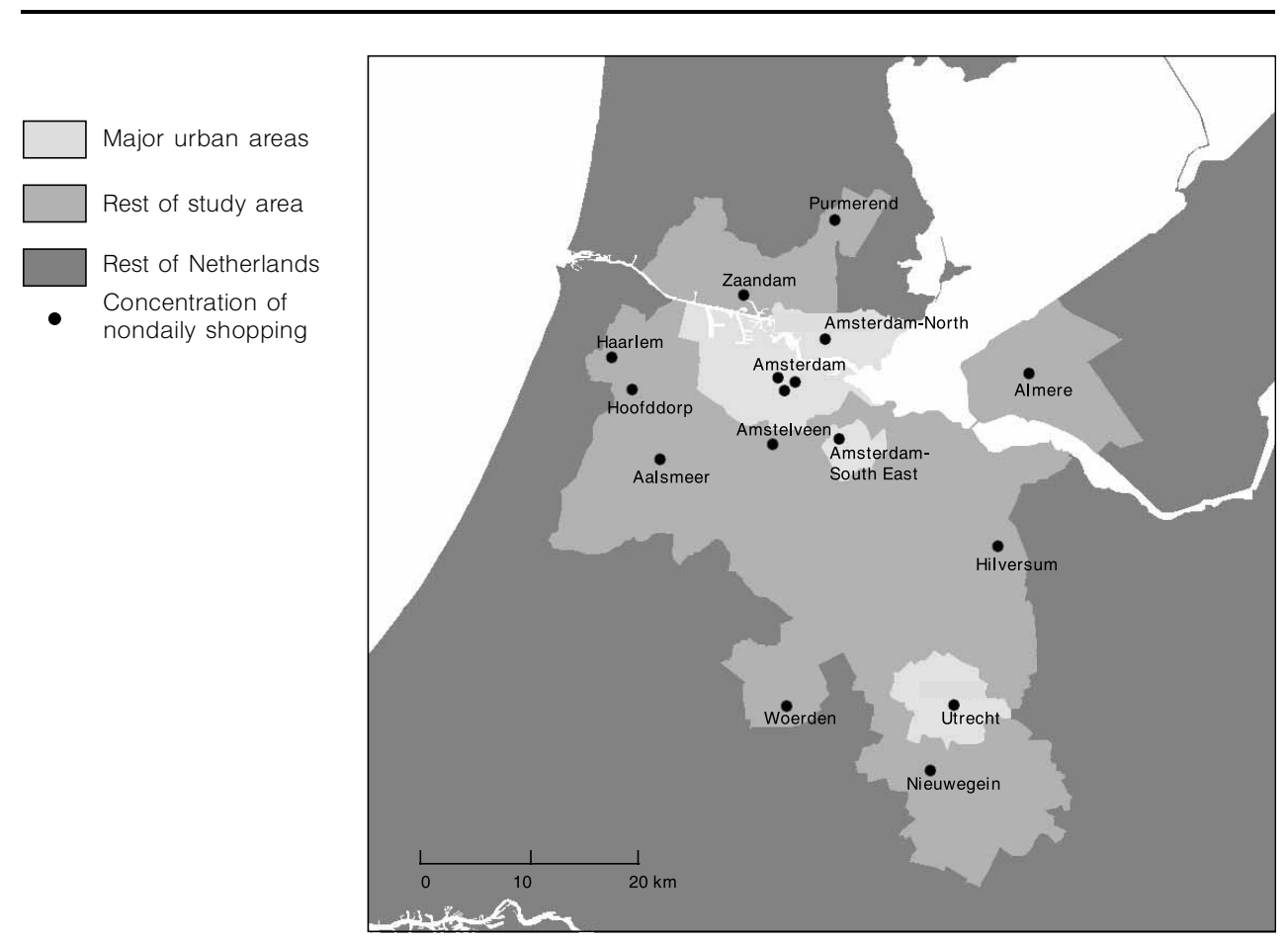

Figure 1. The Amsterdam - Utrecht corridor.

In total 2033 households participated in the AMADEUS survey. All adults in these households were requested to log their activities for two days. Households were allocated to two consecutive days, so that days from Mondays to Fridays are about equally represented in the final data. Weekend days are underrepresented because households were never allocated to the combination Saturday-Sunday. From the original 2033 households, we made the following selection: (i) households with two heads (603 single-headed households excluded); (ii) households with information on gender for both adults (31 households excluded); (iii) only male-female couples (40 same-sex couples excluded); (iv) households conducting at least one out-of-home household activity (79 households excluded); (v) households in which both partners filled out the diary for two days and provided accurate information on the duration of their household activities (267 households excluded). Thus, the sample used for model estimation consists of 790 households. Because the number of same-sex couples in the survey is very small, we expect their exclusion to have no significant impact on the outcomes.

We did not select households on the basis of labour-force participation, which means that dual-worker, single-worker, and nonworking households are all included in the final sample. We readily recognise that task allocation may differ between these household types yet we did not segment the sample along these lines. As outlined before, dual-earner households are usually one-and-a-half-earner households in the Netherlands, implying that the differences between single-worker and dual-worker households are not so clear there as in Anglo-Saxon countries and that employment status is in itself not the most important factor explaining the distribution of out-ofhome tasks. The empirical results below provided support for the argument that distinctions between household types are more fluid in the Netherlands; while dummy indicators for the number of workers in a household yielded no statistically significant results, the number of working hours for each spouse is an important determinant of 
the distribution of out-of-home tasks. Further, the data also contain dual-worker households where only one of the partners works on any of the two days for which he or she logged his or her activities, and there are dual-worker and single-worker households without any working days. These household thus resemble nonworking households in terms of activity scheduling in many ways. Finally, the choice to present models in which dual-worker, single-worker, and nonworking couples are pooled also reflects data limitations. We tried to restrict the analysis to dual-worker households only, but found that the resulting sample is too small for estimation of the coefficients in the models presented below.

For the selected households, we totalled the number of male solo, female solo, and joint episodes for out-of-home household tasks during the two-day period. Out-ofhome household activities are here defined as chauffeuring (a shorthand for dropping off/picking up goods/passengers), grocery shopping, shopping for convenience goods, personal business (visits to post office, bank, library, etc), and 'other' household episodes. This last category mostly consists of episodes in which 'something' has been purchased, or in which both groceries and convenience goods have been bought. Because such episodes are hard to classify, they are excluded from the second model hereafter but retained in the first one. The following rules have been employed to identify activity episodes as joint or independent: first, the episodes of the male and female should be conducted at the same spatial location. Because the activity-diary data are geocoded, this means that the $x$ and $y$ geocoordinates of the centroid of the six-digit zip code area (which usually consist of rows of building facades on one side of a street in between two side streets) should be identical. Second, there should be at least some overlap in terms of timing and duration. While joint episodes can have identical start and end times, they need not be synchronised completely. It is also possible that the episode of one spouse commences earlier and/or lasts longer than that of the other. Third, the male and female episodes need to be identified by both respondents as chauffeuring, grocery shopping, shopping for convenience goods, personal business, or a combination of these.

Descriptive information about the frequency of household episodes is provided in table 1, which shows that joint participation occurs much less frequently than independent engagement. Of all the 4305 household episodes conducted collectively, only $612(14.2 \%)$ have been identified as joint episodes. Joint personal business episodes are especially scarce; these are therefore not considered in the remainder of this paper. Further, we see that, with the exception of personal business, men's participation is clearly lower than women's, reflecting the larger responsibility for domestic labour of the latter.

Because household structure, life cycle, employment status and hours, and access to transport systems all affect activity-travel patterns (Axhausen et al, 2001; Hanson, 1982; Pas, 1984), we have considered household size, the presence and age of children, age, labour force participation, working hours, income, car availability, and ownership of public transport cards as potential determinants in the empirical analysis (table 2). We also identified several location factors and underlying land-use dimensions on the basis of classic studies of the impact of land use on activity-travel patterns and more recent investigations of the impact of New Urbanist neighbourhood designs on car use (Boarnet and Crane, 2001; Hanson, 1982): (i) the population density of the residential zone as an indicator of land-use intensity; (ii) employment density of the residential zone and the proportion of jobs in retailing and services as indicators of land-use diversity; (iii) dummy indicators [(a) city, core area, (b) city, outer area, (c) suburb, inner ring, (d) suburb, outer ring] to represent the distance to the most important activity/employment centres, the city centres of Amsterdam and Utrecht; (iv) accessibility of facilities 
Table 1. Descriptive statistics for out-of-home household episode frequency.

\begin{tabular}{|c|c|c|c|c|c|c|}
\hline \multirow{2}{*}{$\begin{array}{l}\text { Number of } \\
\text { episodes }\end{array}$} & \multicolumn{2}{|c|}{ Female independent } & \multicolumn{2}{|c|}{ Male independent } & \multicolumn{2}{|l|}{ Joint } \\
\hline & $\begin{array}{l}\text { number of } \\
\text { observations }\end{array}$ & $\begin{array}{l}\text { proportion } \\
(\%)\end{array}$ & $\begin{array}{l}\text { number of } \\
\text { observations }\end{array}$ & $\begin{array}{l}\text { proportion } \\
(\%)\end{array}$ & $\begin{array}{l}\text { number of } \\
\text { observations }\end{array}$ & $\begin{array}{l}\text { proportion } \\
(\%)\end{array}$ \\
\hline \multicolumn{7}{|c|}{ All activity types } \\
\hline 0 & 126 & 15.9 & 283 & 35.8 & 610 & 77.2 \\
\hline 1 & 164 & 20.8 & 181 & 22.9 & 0 & 0.0 \\
\hline 2 & 132 & 16.7 & 148 & 18.7 & 105 & 13.3 \\
\hline 3 & 109 & 13.8 & 78 & 9.9 & 0 & 0.0 \\
\hline 4 & 72 & 9.1 & 40 & 5.1 & 47 & 5.9 \\
\hline$\geqslant 5$ & 187 & 23.7 & 60 & 7.6 & 28 & 3.5 \\
\hline \multicolumn{7}{|l|}{ Chauffeuring } \\
\hline 0 & 409 & 51.8 & 491 & 62.2 & 725 & 91.8 \\
\hline 1 & 126 & 15.9 & 134 & 17.0 & 0 & 0.0 \\
\hline 2 & 82 & 10.4 & 100 & 12.7 & 47 & 5.9 \\
\hline 3 & 45 & 5.7 & 30 & 3.8 & 0 & 0.0 \\
\hline 4 & 41 & 5.2 & 15 & 1.9 & $18^{\mathrm{a}}$ & 2.3 \\
\hline$\geqslant 5$ & 87 & 11.0 & 20 & 2.5 & & \\
\hline \multicolumn{7}{|c|}{ Personal business } \\
\hline 0 & 702 & 88.9 & 719 & 91.0 & 784 & 99.2 \\
\hline 1 & 73 & 9.2 & 62 & 7.8 & 0 & 0.0 \\
\hline$\geqslant 2$ & 15 & 1.9 & 9 & 1.1 & 6 & 0.8 \\
\hline \multicolumn{7}{|c|}{ Grocery shopping } \\
\hline 0 & 418 & 52.9 & 610 & 77.2 & 736 & 93.2 \\
\hline 1 & 244 & 30.9 & 121 & 15.3 & 3 & 0.4 \\
\hline 2 & 97 & 12.3 & 47 & 5.9 & $51^{\mathrm{b}}$ & 6.5 \\
\hline$\geqslant 3$ & 31 & 3.9 & 12 & 1.5 & & \\
\hline \multicolumn{7}{|c|}{ Shopping for convenience } \\
\hline 0 & 580 & 73.4 & 681 & 86.2 & 726 & 91.9 \\
\hline 1 & 163 & 20.6 & 86 & 10.9 & 4 & 0.5 \\
\hline 2 & $47^{\mathrm{b}}$ & 5.9 & $23^{\mathrm{b}}$ & 2.9 & 41 & 5.2 \\
\hline 3 & & & & & 0 & 0.0 \\
\hline$\geqslant 4$ & & & & & 19 & 2.4 \\
\hline \multicolumn{7}{|c|}{$\begin{array}{l}\text { a Four or more episodes. } \\
\text { b Two or more episodes. }\end{array}$} \\
\hline
\end{tabular}

as measured by the number of stores (convenience goods as well as total) within a 5 minute and 15 minute drive (both under free-flow traffic conditions), as well as the travel time (free flow) by car to the nearest shopping centre for convenience goods. Such shopping centres were defined as postal code zones with more than 50 persons working in department stores, or zones with more than 150 persons working in stores specialising in clothing and footwear.

The location variables are specified at the four-digit postal code level. The land-use variables are not independent from one another, because the highest population and employment densities can be found in specific parts of the city centres Amsterdam and Utrecht. Bivariate correlation analyses showed that the dummy indicator for residing in the core areas of the major cities is correlated strongly with employment density $(r=0.674)$; these two indicators are therefore not included in the same equations in the model presented below. However, all other bivariate correlation coefficients between land-use indicators in the models in sections $4-5$ fall between -0.35 and +0.35 , suggesting that each variable captures unique aspects of the spatial configuration of land uses. Because nonworking days and nonworking couples are included in 
Table 2. Potential determinants of out-of-home household activity participation. ${ }^{\text {a }}$

\begin{tabular}{|c|c|c|c|}
\hline Variable name & Description & $\begin{array}{l}\text { Mean/ } \\
\text { share }\end{array}$ & $\mathrm{SD}$ \\
\hline \multicolumn{4}{|l|}{ Sociodemographics and access to transport systems } \\
\hline Household size $^{*}$ & Number of persons in the household & 3.03 & 1.11 \\
\hline No child & Couple without coresident children (\%) & 50.9 & \\
\hline Child aged $0-5^{*}$ & Couple with youngest child $0-5$ years old $(\%)$ & 25.2 & \\
\hline Child aged $6-11$ & Couple with youngest child $6-11$ years old $(\%)$ & 14.6 & \\
\hline Child aged $12-17$ & Couple with youngest child $12-17$ years old $(\%)$ & 9.5 & \\
\hline Dual-worker couple & Couple with two employed adults $(\%)$ & 56.7 & \\
\hline Single-worker couple & Couple with one employed adult $(\%)$ & 31.9 & \\
\hline Nonworker couple & Couple without employed adults $(\%)$ & 10.9 & \\
\hline Working/education hours, male* & Average number of weekly hours the male partner spends on work and education & 31.8 & 19.0 \\
\hline Working/education hours, female* & Average number of weekly hours the female partner spends on work and education & 17.7 & 16.5 \\
\hline High household income* & Gross annual household income two or more times above the model income $(> \pm$ euro 40.000$)(\%)$ & 61.3 & \\
\hline Aged $<30$ & Couple with oldest adult $<30$ years old $(\%)$ & 6.3 & \\
\hline Aged $30-59$ & Couple with oldest adult $30-59$ years old $(\%)$ & 80.0 & \\
\hline Aged $>60$ & Couple with oldest adult aged $\geqslant 60$ years $(\%)$ & 13.7 & \\
\hline Train card, male* & Male holds annual/season ticket for train $(\%)$ & 31.5 & \\
\hline Train card, female* & Female holds annual/season ticket for train $(\%)$ & 33.8 & \\
\hline Bus/tram/metro card, male* & Male holds annual/season ticket for bus/tram/metro (\%) & 9.9 & \\
\hline Bus/tram/metro card, female* & Female holds annual/season ticket for bus/tram/metro $(\%)$ & 10.1 & \\
\hline Car availability, male* & Car availability for male $(0=$ not available; $1=$ available after deliberation; $2=$ always available $)$ & 1.54 & 0.60 \\
\hline Car availability, female* & Car availability for female (categories as for male) & 1.36 & 0.61 \\
\hline \multicolumn{4}{|l|}{ Location characteristics ${ }^{\mathrm{a}}$} \\
\hline Population density* & Number of inhabitants per hectare & 36.2 & 34.7 \\
\hline Employment density* & Number of jobs in the neighbourhood per hectare & 15.5 & 29.9 \\
\hline Service employment & Share of service jobs in total number of jobs in the neighbourhood & 5.7 & 7.5 \\
\hline Retail employment* & Share of retail jobs in total number of jobs in the neighbourhood & 9.3 & 7.4 \\
\hline City, core area* ${ }^{*}$ & Neighbourhood located in the core area of Amsterdam or Utrecht $(\%)$ & 5.3 & \\
\hline City, outer area & Neighbourhood located in other areas of Amsterdam or Utrecht (\%) & 25.9 & \\
\hline Suburb, inner ring & Neighbourhood located in suburbs near Amsterdam or Utrecht $(\%)$ & 40.8 & \\
\hline Suburb, outer ring & Neighbourhood located at larger distance from Amsterdam or Utrecht (\%) & 28.0 & \\
\hline Travel time to nearest department store & Auto travel time to nearest spatial concentration of department stores ( $>50$ jobs in department store) & 8.40 & 4.97 \\
\hline $\begin{array}{l}\text { Travel time to nearest concentration of shops } \\
\text { for clothing/footwear }\end{array}$ & Auto travel time to nearest spatial concentration of clothing/footwear stores ( $>150$ jobs in clothing/footwear) & 7.01 & 4.05 \\
\hline Total stores within 5 minutes & Total number of stores within 5 minute auto travel time & 991.8 & 1063.5 \\
\hline Stores for convenience goods within 5 minutes & Number of nondaily retailing jobs within 5 minute auto travel time & 834.5 & 909.4 \\
\hline Total stores within 15 minutes & Total number of shops available within 15 minute auto travel time & 7501.1 & 4467.9 \\
\hline Stores for convenience goods within 15 minutes & Number of nondaily shops available within 15 minute auto travel time & 6274.9 & 3743.2 \\
\hline \multicolumn{4}{|c|}{${ }^{*}$ Included in the path models (sections 5 and 6 ). } \\
\hline
\end{tabular}

Sociodemographics and access to transport system Household size

No child

Child aged $0-5$

Dual-worker couple

Single-worker coupl

Nonworker couple

Aged $<30$

Aged $30-59$

Aged $>60$

Bus/tram/metro card, male*

metro card, female

Car availability, female

Location characteristics ${ }^{\text {a }}$

Population density*

City, core area

Suburb, inner

Travel time to nearest department store

Travel time to nearest concentration of shops

Stores for convenience goods within 5 minutes

Couple with youngest child $0-5$ years old $(\%)$

Couple with youngest child $6-11$ years old $(\%)$

Couple with two employed adults $(\%)$

Couple with one employed adult $(\%)$

Average number of weekly hours the male partner spends on work and education

with oldest adult $30-59$ years old $(\%)$

Female holds annual/season ticket for train $(\%)$

Male holds annual/season ticket for bus/tram/metro (\%)

Number of inhabitants per hectare

Number of jobs in the neighbourhood per hectare

Share of service jobs in total number of jobs in the neighbourhoo

Neighbourhood located in other areas of Amsterdam or Utrecht $(\%)$

od located in suburbs near Amsterdam or Utrecht $(\%)$

Neighbourhood located at larger distance from Amsterdam or Utrecht $(\%)$

Auto travel time to nearest spatial concentration of department stores $(>50$ jobs in department store)

Total number of stores within 5 minute auto travel time

Number of nondaily retailing jobs within 5 minute auto travel time

501

467.9

* Included in the path models (sections 5 and 6) 
the data for estimation, we did not specify land-use variables centred on respondents' workplace, although we acknowledge that these may also influence workers' conduct of out-of-home tasks (eg Nishii and Kondo, 1992). There is some evidence, however, that household activities during commutes are conducted more often at the home end than at the workplace end in the Netherlands (Verburg et al, 2005). Overall, we expect that the omission of workplace-related location factors will not introduce serious bias to the analysis results. The impact of land-use characteristics of workplace locations should nonetheless be addressed explicitly in future studies.

\subsection{Model structure and estimation}

Decisions about participation in household activities form part of the household activity scheduling process and cannot be investigated in isolation from one another. Men's and women's individual and joint engagement frequencies are therefore treated as endogenous variables that are influenced by exogenous variables and that at the same time serve as explanatory variables for each other. Path analysis, a flexible framework for testing two-way causal relationships, is used to allow activity participation variables to feature simultaneously as dependent and explanatory variables. Path models are a specific form of simultaneous equation models in which the assumption is made that observed variables are perfect measurements of underlying latent constructs (Golob, 2003). In the analysis, covariance analysis has been used to estimate the coefficients of the path model. A model covariance matrix is fitted on a sample covariance matrix, while the differences between the predicted and observed values are iteratively minimised. Maximum likelihood estimation was used as the method of estimation because there are many ordinal variables in our analysis (see Jöreskog, 2001). In this way, standard errors and $\chi^{2}$-statistics are corrected for nonnormality.

Path analysis is attractive because it distinguishes between indirect, indirect, and total effects of variables. A total effect equals the sum of a direct effect and all indirect effects. For example, the frequency of shopping for consumer goods is influenced directly by grocery shopping (ie, persons conducting many grocery shopping episodes may also engage more frequently in shopping for consumer goods), and indirectly by grocery shopping via personal business (ie, persons conducting many grocery shopping episodes may also participate more often in shopping for consumer goods because they engage more frequently in personal business activities).

A wide range of indicators has been proposed for determining the model goodnessof-fit. Golob (2003) recommends the use of several goodness-of-fit indicators at the same time. We therefore employ the Satorra-Bentler $\chi^{2}$ which is corrected for nonnormality, as well as the standardised root mean square residual (SRMR) and root mean square error of approximation (RMSEA). The RMSEA provides information on the degree of the discrepancy between the observed and estimated covariance matrices. The SRMR indicates the root of the average of the squared residuals. The closer to zero the values of both indices are, the smaller is the 'misfit' associated with the estimated model. Values below 0.05 indicate that the specified model fits the data well.

\subsection{Model specification}

Two model systems are specified - one for the total household episode frequency with three endogenous variables, and one with eleven endogenous variables with the number of episodes segmented by activity type. In both model systems, household structure, life cycle, working hours, access to transport systems, and location factors are assumed to be exogenous to the generation and scheduling of out-of-home household activities.

The models presented hereafter are exploratory in nature. Given the complexity in the between-spouses interactions in activity participation, we did not a priori specify a complete theoretical model to be tested against the data. Instead, we made modifications 
to a set of hypothesised relations on the basis of empirical tests. More specifically, we started by estimating single-equation regression models for all endogenous variables in which all variables in table 2 were allowed to be included as determinants. Variables with statistically significant coefficients in those models (marked with asterisks in table 2) were allowed to be included in the path models. The final specifications of the path models were based on conceptual plausibility and statistical tests. Two types of tests have been used: tests using the Satorra-Bentler $\chi^{2}$-statistic for the whole model and $t$-tests on individual direct effects. In some instances, variables whose direct effects were borderline significant have been retained in the final specification because they are of interest theoretically. The reader should note that total effects need not be statistically significant even if all direct effects are significant, because indirect effects may cancel out one another or direct effects. Conceptual plausibility is based on two considerations. Firstly, there is no a priori limitation of mutual influence between male, female, and joint activities; each mode of engagement can be influenced by the two other modes. Secondly, causal relationships between different types of household activities depend on the space-time fixity of activity types: more fixed activities influence the participation in more flexible activities but the reverse is not allowed. Chauffeuring is assumed to be the most fixed in space and time, followed by grocery shopping, personal business, and convenience shopping. Within the limitations of this fixity hierarchy, all modes of engagement can influence each other.

\section{Total frequency of household activities}

This section describes the model system for the total number of household activity episodes. Standardised coefficients for the direct and total effects are presented in table 3. According to the goodness-of-fit indicators, the model fits the data very well. In terms of relationships among the endogenous variables, we find that the frequency of male independent episodes has a negative effect on female independent participation. The latter, in turn, has a direct negative effect on joint participation. Therefore, a (small) positive total effect of male participation on joint participation can also be observed. In other words, a more active role of the male in out-of-home household tasks does not imply an equally large reduction in his partner's responsibilities.

With respect to the exogenous variables, we find that a larger household size results in a household-level task specialisation in the sense that females' independent participation increases at the expense of joint participation. The presence of a young child implies that both males' and females' independent engagement increases, and by implication also that joint participation is to some extent reduced. On balance, the impact is somewhat larger for men than for women, which is not fully consistent with expectations (section 2). The coefficients for the weekly time devoted to work and education show that longer hours reduce the participation in out-of-home household activities for both men and women, although the impact is stronger for males. If the female spends more time on employment or education, household tasks are shifted to the male spouse though joint participation also increases slightly. In contrast, if men work more or spend more time on education, this has few ramifications for women's activity patterns. Thus, while responsibilities are transferred to their partner if women spend more time on work/education, men's working/education hours are merely associated with a reduction in and rationalisation of their participation in out-of-home household tasks. These findings thus differ from those in various earlier studies (Hanson and Hanson, 1981; Pinch and Storey, 1992). The impact of household income on the allocation of household responsibilities is fairly limited. We only find that joint participation in high-income households is lower than in low-income and medium-income households. 
Table 3. Standardised coefficients in the path model for the total out-of-home household episode frequency, by mode of engagement.

\begin{tabular}{|c|c|c|c|}
\hline & Female & Male & Joint \\
\hline \multicolumn{4}{|l|}{ Direct effects } \\
\hline \multicolumn{4}{|l|}{ Endogenous variable } \\
\hline Male household episode frequency & -0.137 & & \\
\hline Female household episode frequency & & & -0.204 \\
\hline \multicolumn{4}{|l|}{ Exogenous variables } \\
\hline Household size & 0.324 & & -0.161 \\
\hline Child aged $0-5$ & 0.249 & 0.298 & \\
\hline Working/education hours, male & & -0.215 & \\
\hline Working/education hours, female & & 0.129 & \\
\hline High household income & & & -0.131 \\
\hline Car availability, female & & -0.142 & 0.153 \\
\hline Train card, male & -0.067 & 0.074 & \\
\hline Train card, female & 0.298 & -0.066 & \\
\hline Bus/tram/metro card, male & 0.136 & -0.161 & -0.036 \\
\hline Bus/tram/metro card, female & -0.309 & 0.199 & \\
\hline Employment density & & 0.049 & \\
\hline $\begin{array}{l}\text { Travel time to nearest concentration of shops for } \\
\text { clothing/footwear }\end{array}$ & & & 0.080 \\
\hline City, core area & & & 0.076 \\
\hline \multicolumn{4}{|l|}{ Total effects } \\
\hline \multicolumn{4}{|l|}{ Endogenous variable } \\
\hline Male independent & -0.137 & & 0.028 \\
\hline Female independent & & & -0.204 \\
\hline \multicolumn{4}{|l|}{ Exogenous variable } \\
\hline Household size & 0.324 & & -0.277 \\
\hline Child aged $0-5$ & 0.208 & 0.298 & -0.042 \\
\hline Working/education hours, male & $0.029^{\mathrm{b}}$ & -0.215 & -0.006 \\
\hline Working/education hours, female & -0.018 & 0.129 & 0.004 \\
\hline High household income & & & -0.131 \\
\hline Car availability, female & $0.019^{\mathrm{b}}$ & -0.142 & 0.149 \\
\hline Train card, male & $-0.077^{\mathrm{a}}$ & 0.074 & 0.016 \\
\hline Train card, female & $0.307^{\mathrm{b}}$ & -0.066 & -0.063 \\
\hline Bus/tram/metro card, male & $0.158^{\mathrm{a}}$ & -0.161 & -0.069 \\
\hline Bus/tram/metro card, female & -0.336 & 0.199 & 0.069 \\
\hline Employment density & -0.007 & 0.049 & 0.001 \\
\hline $\begin{array}{l}\text { Travel time to nearest concentration of shops for } \\
\text { clothing/footwear }\end{array}$ & & & 0.080 \\
\hline City, core area & & & 0.076 \\
\hline
\end{tabular}

Note: Goodness-of-fit indicators: Satorra-Bentler $\chi^{2}=13.08$ with $d f=19$ and $p=0.835$; standardised root mean square residual $(\mathrm{SRMR})=0.018$; root mean square error of approximation $($ RMSEA) $=0.00$ with $p$-value of test for close fit $($ RMSEA $>0.05)=1.00$.

${ }^{a}$ Coefficients are statistically significant at $0.05<p<0.10$;

b Coefficients are not statistically significant at $p<0.10$; nonmarked coefficients are statistically significant at $p<0.05$.

Perhaps higher-income households, which tend to be dual-earner couples, are more sensitive to the higher coordination costs of joint out-of-home household tasks.

Various indicators of transport access influence household's decisions about household activity participation. As the female enjoys better car accessibility, her spouse's independent participation is reduced and joint participation increases. While one would expect women to pursue more activities independently if they enjoy better car availability (Gliebe and Koppelman, 2002), these results suggest that spouses may 
engage in joint household activities for reasons of altruism and/or companionship. For both men and women, train-card ownership is associated with more solo episodes but with fewer activities by their partners. The opposite is true for bus/tram/metro cards: men and women holding such a card tend to engage less frequently in out-of-home household activities but their partners take part in these activities more often. The effects for the bus/tram/metro suggest that these transport systems are not well suited for shopping and chauffeuring trips (see Dowling, 2000). The effects of train cards seem to reflect that there are many services and shops for groceries and convenience goods available in and/or directly adjacent to many train stations, where travellers can halt when changing means of transport.

Three location factors affect the distribution of household responsibilities for the couples in our sample. As expected, men's solo participation is larger if the employment density of the residential neighbourhood is higher. Because of this, women's independent participation is somewhat lower and joint participation is slightly higher in more diverse neighbourhoods. Overall, however, women's responsibility for out-ofhome household activities is lower in neighbourhoods with more land-use diversity. Nonetheless, household's total participation in out-of-home household tasks becomes larger with increasing employment densities, suggesting that men's larger role mainly reflects additional activities not undertaken by households in neighbourhoods with low levels of land-use diversity.

The estimation results also indicate that joint participation increases as the travel time to the nearest major shopping centre for clothing/footwear increases. In the Dutch context, these centres coincide with more general concentrations of stores and facilities to be found mainly in the core areas of larger settlements in the Amsterdam Utrecht area (see figure 1). This finding may thus be interpreted as indicating that couples tend to pool resources to overcome lower levels of accessibility to major concentrations of shops and other facilities. At the same time, we find that couples living in the central areas of Amsterdam and Utrecht, where the largest concentrations of (higher order) shops and services in the study area can be found, are also inclined to conduct household activities together more frequently. Residing in or very near to major concentrations of shops and other facilities may thus also stimulate joint participation in household activities. Perhaps couples residing in the central parts of Amsterdam Utrecht consider joint visits to the nearby concentration of shops and services more often as opportunities to spend time together than spouses in other neighbourhoods do. They may, for instance, mix the conduct of out-of-home chores with joint, more leisure-oriented strolls through the nearby shopping district.

\section{Episode frequency by type of household activity}

\subsection{Endogenous variables}

The results for the relations among the endogenous variables are presented in tables $4-5$ and figure 2 . In figure 2, arrows in the vertical direction outnumber horizontal and diagonal arrows. More direct relations can be observed among different activities conducted by the female alone, the male alone, or jointly than among different participation modes for a given activity type. This suggests that the female solo, male solo, and joint participation in a given activity type function only to a limited extent as substitutes for one another. The major exception to this finding is grocery shopping where more independent episodes by women reduce male independent and joint participation. There are also few diagonal lines depicted in figure 2 . Those that are statistically significant are all related to activities pursued by men.

Further, we see that, with the exception of the relation between chauffeuring activities by men and shopping for convenience goods by men, all effects in the vertical 
Table 4. Standardised direct effects in the path model for out-of-home household episode frequency by activity type and mode of engagement.

\begin{tabular}{|c|c|c|c|c|c|c|c|c|c|c|c|}
\hline \multirow[t]{3}{*}{ Explanatory variable } & \multicolumn{11}{|c|}{ Dependent variable } \\
\hline & \multicolumn{3}{|c|}{ chauffeuring } & \multicolumn{3}{|c|}{ groceries } & \multicolumn{2}{|c|}{ personal business } & \multicolumn{3}{|c|}{ convenience goods } \\
\hline & female & male & joint & female & male & joint & female & male & female & male & joint \\
\hline \multicolumn{12}{|l|}{ Endogenous variables } \\
\hline Chauffeuring, female & & & & & & & & & 0.114 & & \\
\hline Chauffeuring, male & & & 0.200 & & & & & 0.131 & & -0.105 & \\
\hline Chauffeuring, joint & & & & & & & & -0.356 & & & \\
\hline Groceries, female & & & & & -0.172 & -0.241 & 0.273 & & 0.197 & & \\
\hline Groceries, male & & & & & & & & 0.453 & & 0.245 & -0.127 \\
\hline Groceries, joint & & & & & & & & 0.221 & & & 0.525 \\
\hline Personal business, female & & & & & & & & & 0.228 & & \\
\hline Personal business, male & & & & & & & & & & 0.226 & \\
\hline \multicolumn{12}{|l|}{ Exogenous variables } \\
\hline Household size & 0.347 & & $-0.136^{\mathrm{a}}$ & 0.153 & 0.190 & & & -0.234 & & 0.091 & \\
\hline Child aged $0-5$ & 0.391 & 0.455 & & & & -0.401 & & & & & \\
\hline Working/education hours, male & & -0.116 & & 0.118 & -0.210 & & & & & & \\
\hline Working/education hours, female & & 0.155 & & -0.123 & 0.100 & & & & & & \\
\hline High household income & & & & & & & & & & & -0.056 \\
\hline Car availability, male & & 0.115 & & & & & & & & & \\
\hline Car availability, female & & -0.207 & & & & & & & & & \\
\hline Train card, male & & $-0.054^{\mathrm{a}}$ & & & 0.127 & & & 0.076 & & 0.158 & \\
\hline Train card, female & 0.157 & & & & & & 0.308 & & & & 0.180 \\
\hline Bus/tram/metro card, male & & & & & -0.205 & & & & & & -0.236 \\
\hline Bus/tram/metro card, female & -0.115 & & & & 0.204 & & $-0.105^{\mathrm{a}}$ & & & -0.109 & \\
\hline Proportion retail & & & & -0.105 & & & & $-0.144^{\mathrm{a}}$ & & 0.098 & \\
\hline $\begin{array}{l}\text { Time to nearest concentration of } \\
\text { shops for clothing/footwear }\end{array}$ & & & & & & & & -0.142 & 0.089 & 0.125 & \\
\hline City, core area & & & & & & & -0.293 & -0.340 & $0.127^{\mathrm{a}}$ & 0.222 & \\
\hline Population density & & & & & 0.179 & & & & & & \\
\hline \multicolumn{12}{|c|}{$\begin{array}{l}\text { Note: Goodness-of-fit indicators: Satorra-Bentler } \chi^{2}=114.3 \text { with } d f=162 \text { and } p=0.837 \text {; standardised root mean square residual }(\text { SRMR) }=0.047 \text {; } \\
\text { root mean square error of approximation }(\text { RMSEA) }=0.00 \text { with } p \text {-value of test for close fit }(\text { RMSEA }>0.05)=1.00 \text {. } \\
\text { a Coefficients are statistically significant for } p<0.10 \text {; nonmarked coefficients are for statistically significant for } p<0.05 \text {. }\end{array}$} \\
\hline
\end{tabular}


Table 5. Standardised total effects in the path model for out-of-home household episode frequency by activity type and mode of engagement.

\begin{tabular}{|c|c|c|c|c|c|c|c|c|c|c|c|}
\hline \multirow[t]{3}{*}{ Explanatory variable } & \multicolumn{11}{|c|}{ Dependent variable } \\
\hline & \multicolumn{3}{|c|}{ chauffeuring } & \multicolumn{3}{|c|}{ groceries } & \multicolumn{2}{|c|}{ personal business } & \multicolumn{3}{|c|}{ convenience goods } \\
\hline & female & male & joint & female & male & joint & female & male & female & male & joint \\
\hline \multicolumn{12}{|l|}{ Endogenous variables } \\
\hline Chauffeuring, female & & & & & & & & & 0.114 & & \\
\hline Chauffeuring, male & & & 0.200 & & & & & 0.056 & & -0.092 & \\
\hline Chauffeuring, joint & & & & & & & & -0.377 & & -0.085 & \\
\hline Groceries, female & & & & & -0.172 & -0.241 & 0.273 & -0.131 & 0.259 & -0.072 & -0.105 \\
\hline Groceries, male & & & & & & & & 0.453 & & 0.348 & -0.127 \\
\hline Groceries, joint & & & & & & & & 0.221 & & 0.050 & 0.525 \\
\hline Personal business, female & & & & & & & & & 0.228 & & \\
\hline Personal business, male & & & & & & & & & & 0.226 & \\
\hline \multicolumn{12}{|l|}{ Exogenous variables } \\
\hline Household size & 0.347 & & $-0.136^{\mathrm{a}}$ & 0.153 & 0.164 & -0.037 & 0.042 & $-0.117^{\mathrm{a}}$ & 0.079 & $0.105^{\mathrm{a}}$ & -0.040 \\
\hline Child aged $0-5$ & 0.391 & 0.455 & 0.091 & & & -0.401 & & $-0.063^{\mathrm{b}}$ & 0.045 & -0.062 & -0.211 \\
\hline Working/education hours, male & & -0.116 & $-0.023^{\mathrm{b}}$ & 0.118 & -0.230 & $-0.028^{b}$ & $0.031^{\mathrm{b}}$ & -0.117 & 0.031 & $-0.071^{\mathrm{a}}$ & $-0.014^{\mathrm{b}}$ \\
\hline Working/education hours, female & & 0.155 & 0.031 & -0.123 & 0.121 & 0.030 & -0.033 & 0.070 & -0.034 & 0.029 & $0.000^{\mathrm{b}}$ \\
\hline Car availability, male & & 0.115 & 0.023 & & $-0.113^{a}$ & & & $-0.045^{\mathrm{b}}$ & & $-0.011^{\mathrm{b}}$ & \\
\hline Car availability, female & & -0.207 & -0.041 & & & & & -0.012 & & 0.019 & \\
\hline Train card, male & & $-0.054^{\mathrm{a}}$ & $-0.011^{\mathrm{b}}$ & & 0.127 & & & $0.130^{\mathrm{b}}$ & & 0.225 & -0.016 \\
\hline Train card, female & 0.157 & & & & & & 0.308 & & 0.088 & & 0.180 \\
\hline Bus/tram/metro card, male & & & & & -0.205 & & & -0.093 & & $-0.071^{\mathrm{a}}$ & -0.210 \\
\hline Bus/tram/metro card, female & -0.115 & & & & 0.204 & & $-0.105^{\mathrm{a}}$ & 0.092 & -0.037 & $-0.038^{\mathrm{b}}$ & $\begin{array}{l}-0.026 \\
-0.056\end{array}$ \\
\hline High household income & & & & & & & & & & $0073 \mathrm{~b}$ & $\begin{array}{r}-0.056 \\
0.011\end{array}$ \\
\hline Proportion retail & & & & -0.105 & 0.018 & 0.025 & $-0.029^{\circ}$ & $-0.131^{\mathrm{b}}$ & $-0.027^{\mathrm{a}}$ & $0.073^{\mathrm{b}}$ & 0.011 \\
\hline $\begin{array}{l}\text { Time to nearest concentration of } \\
\text { shops for clothing/footwear }\end{array}$ & & & & & & & -0.142 & & $0.057^{\mathrm{a}}$ & 0.125 & \\
\hline City, core area & & & & & & & -0.340 & -0.293 & $0.049^{\mathrm{a}}$ & $0.155^{\mathrm{b}}$ & \\
\hline Population density & & & & & 0.179 & & & 0.081 & & 0.062 & -0.023 \\
\hline
\end{tabular}

a Coefficients are statistically significant for $p<0.10$ but not for $p<0.05$;

${ }^{\mathrm{b}}$ Coefficient not statistically significant for $p<0.10$; nonmarked coefficients are statistically significant for $p<0.05$. 


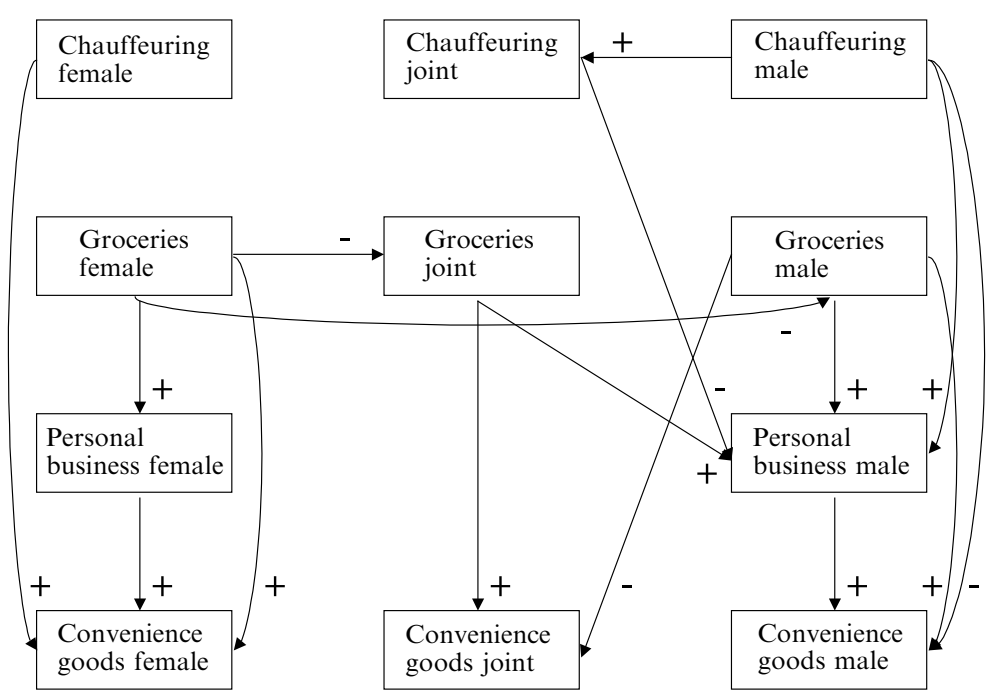

Figure 2. Direct effects between endogenous variables.

direction are positive. This suggests complementary relations among activity types and task specialisation within households: if a female or a male engages more frequently independently in one activity type, he or she is also likely to conduct other activities more often alone. The negative relation between chauffeuring and shopping for convenience goods for men (as well as the two diagonal arrows discussed before) suggests that men make more trade-offs and are somewhat more selective in their participation in out-of-home household tasks than women. Gender-role constraints may prevent women from exercising the same level of discretion over participation in out-of-home household activities as men (Aitken, 2000; Kwan, 1999; 2000).

\subsection{Sociodemographics and access to transport systems}

The direct and total effects suggest that a larger household size results in a householdlevel specialisation in chauffeuring, with the female conducting more solo tasks and with a reduction of joint participation. Males' and females' independent participation in grocery shopping is higher in larger households (table 4), also implying fewer joint episodes (table 5). The total effects reveal a similar pattern for shopping for convenience goods. Finally, men engage less often in personal business in larger households but women somewhat more often. Collectively, these findings suggest that more weight is given to efficient activity scheduling in larger households, resulting especially in more individual household activities for women. As expected, the presence of a young child increases the use of all modes of chauffeuring participation, but reduces joint shopping for groceries and convenience goods. This seems to reflect coupling constraints whereby one parent needs to mind the child(ren). The total effects further reveal a shift in shopping for convenience goods from the male to his partner, who may take the child(ren) with her when she goes shopping.

As men spend more time on work and education, their independent participation in all domestic activities is reduced, suggesting intrapersonal trade-offs between working/education hours and household tasks. For women, such intrapersonal constraints are observed for shopping and personal business but not for chauffeuring activities. This suggests that gender-role constraints mean that especially the participation in chauffeuring is more obligatory for women than for men (see Kwan, 1999; 2000). There are also many cross-person impacts, most of which are indirect effects. If women 
allocate more time to work or education on a weekly basis, men engage more often in all activity types (table 5). Additionally, if men spend more time on work or education, women conduct more shopping for both groceries and convenience goods. Further, we see that the frequency of joint episodes for chauffeuring and grocery shopping is higher, as women spend more time on work and education. Perhaps couples where the female works longer hours are more likely to engage in joint activities for reasons of companionship because such activities offer (employed) spouses the opportunity to spend time together. Nonetheless, the net outcome is that women's participation in outof-home household activities is not reduced to the same extent as men's role increases with longer working/education hours for women.

The impact of having a high household income is restricted to a negative effect on the frequency of joint shopping for convenience goods. As in the general model, it is hypothesised that a higher household income is characteristic of dual-earner households, for which it is more difficult to schedule joint activities in the light of busy activity agendas. Apparently, this holds primarily for convenience goods shopping, which is more discretionary in nature than other activities and is therefore the first to be replaced by individual engagement or not undertaken at all.

While men's car availability had no impact on the overall frequency of household activities, it has a positive effect on solo chauffeuring activities and, through that, on joint chauffeuring. As before, women's car availability is more important for domestic tasks. If women have better access to a car, men chauffeur less and joint chauffeuring is reduced. Having access to a car thus increases women's independence in the scheduling of chauffeuring tasks. Men also conduct fewer personal business activities but more shopping for convenience goods if females enjoy better car availability. These findings may reflect that, in households with two cars, tasks are less rigidly allocated to specific spouses and activity schedules can be revised more easily.

If the male holds a train card, he will participate less in solo and joint chauffeuring but more in personal business and shopping. The latter effects may reflect the presence of many services and shops on major train stations whose availability facilitates visits to such facilities when travelling by train. If the female holds a train card, she engages more often in personal business and solo and joint shopping for convenience goods. No other cross-person effects of holding a train card were detected.

Finally, if men hold a bus/tram/metro card, they engage less in grocery shopping trips, which reflects the inconvenience of using a bus/tram/metro for this kind of activity. They also engage less in joint shopping for convenience goods, probably because dependence on a bus/tram/metro makes it more difficult to schedule joint activities. If women hold a bus/tram/metro card, they make fewer chauffeuring trips and men take over some of the grocery shopping trips. The total effects also suggest that reliance on a bus/tram/metro reduces a women's participation in out-of-home household activities, part of which is compensated for by a transfer of responsibilities to their partners.

\subsection{Location factors}

Although we tested many location factors (table 2), only four are statistically significantly related to at least one of the endogenous variables in the path model. Two of these specifically relate to the availability of retail services, which is due to the importance of shopping activities within the broader class of household activities. Yet, this also reflects that shops and other facilities and services are often mixed and concentrated in (local) activity centres. The availability of retail functions in an area usually implies the presence of other kinds of facilities. 
The proportion of retail jobs in the total employment per four-digit postal code area is one indicator of retail availability. As this percentage increases, women engage less frequently in shopping for groceries and convenience goods independently and men's solo and joint participation becomes larger (table 5). However, the reduction in women's responsibilities does not equal men's larger role in grocery shopping, because joint participation is also higher in locations with more local shopping opportunities. This higher inclination for joint activities may reflect altruism and companionship motivations. For shopping for consumer goods, there is also a negative relationship between local shopping opportunities and women's solo participation. However, the evidence for a shift of responsibilities between partners is less clear in this case, because joint participation is also higher and the (positive) total impact on men's solo participation is not statistically significant. Thus, there are only relative differences in the partner's responsibilities for shopping for consumer goods between neighbourhoods with few and many local shopping opportunities.

The results for the second retail-related variable, the travel time to the nearest shopping centre for clothing or footwear, suggest that women and especially men participate more frequently in shopping for convenience goods independent of their spouse, as the travel time rises. The explanation of this finding is not entirely clear. However, males' and especially female's solo participation in shopping for consumer goods is also higher among households near the concentrations of specialised shops, services, and other facilities in the inner areas of Amsterdam and Utrecht. Thus, there is no unambiguous evidence of a lower responsibility for shopping for consumer goods by women among households near major concentrations of specialised shops and other facilities.

Finally, the population density of the residential neighbourhood has a positive direct effect on men's solo grocery shopping, and, through that, on their personal business activities and solo shopping for convenience goods. Thus, men play a larger role in out-of-home household activities in higher density neighbourhoods. Population density also has a negative impact on the frequency of joint shopping for convenience goods, suggesting that the coordination costs of joint participation are too high when individuals have more opportunities for undertaking solo activities. Note, however, that there is no impact on women's solo participation. Men in higher density locations participate in additional grocery shopping and personal business activities not undertaken in lower density neighbourhoods; women's responsibilities for these activities decrease only in a relative but not an absolute sense. Because of the negative effect of population density on joint episodes, there is a slight reduction in women's absolute role in shopping for consumer goods in high-density neighbourhoods.

In summary, the impact of land use on how partners organise their household activities is complex. Nonetheless, all else being equal, women in neighbourhoods with a higher population density and more diverse land uses carry less responsibility for shopping and personal business, because their partners engage more in shopping for groceries and consumer goods. The reduction of women's responsibilities does not equal men's larger role, however, because joint participation in shopping is also somewhat higher in high-density, mixed-use neighbourhoods. The outcomes further indicate that the allocation of chauffeuring duties does not depend on location factors.

\section{Conclusions}

This paper has sought to enhance our understanding of the distribution of out-of-home household tasks between spouses. Path analysis has been employed to investigate how location factors affect the frequency of female solo, male solo, and partners' joint household activity episodes among couples in the Amsterdam - Utrecht corridor, while taking household structure, life cycle, employment status and hours, access to 
transport systems, and interactions among activities in persons' activity schedules into consideration. In line with numerous other studies (eg Hanson and Pratt, 1995; Morris, 1990), the analysis suggests that women perform the bulk of out-of-home household activities among couples in the samples and that the impact of factors such as working hours, presence of young children, and car availability is gender specific.

The study has also shown that the distribution of household tasks between partners is more equal in higher density, more diverse neighbourhoods. Men tend to undertake more out-of-home chores in such areas, but this does not result in an equally large reduction in women's participation in these tasks. This is because part of men's more intensive participation in household activities consists of joint shopping activities with their partner, which seem to be motivated primarily by considerations of companionship and/or altruism. Further, some of the grocery shopping and personal business activities by men in denser neighbourhoods reflect activities not undertaken in other locations. This implies that the shift in responsibilities from women to men is larger in a relative than in an absolute sense. For chauffeuring activities, which tend to be more fixed in space and time than other household activities, there is no impact of location on women's and men's solo and joint participation. These results suggest that it is important to consider activity type and whether activities are undertaken independently or jointly when studying the distribution of household tasks between spouses, given that the impact of location factors is larger for more discretionary activity types.

Although this study has suggested the relevance of location factors to investigations of tasks allocation within households, we emphasise that their role is smaller than that of sociodemographics and access to transport systems. Other studies about the impact of location factors on activity - travel patterns have reached similar conclusions (Boarnet and Crane, 2001; Hanson, 1982; Pas, 1984). This paper has, nonetheless, shown that decisions about activity participation and allocation do not take place in a geographical vacuum, but at least to some extent depend on households' spatial context. Location should therefore be explicitly considered in future studies of the allocation of household chores.

Acknowledgements. The work by Schwanen on this paper was made possible by grant 451.03 .058 from the Netherlands Organisation for Scientific Research. We gratefully acknowledge the comments of the reviewers and editor, which have improved the paper.

\section{References}

Aitken S C, 2000, "Fathering and faltering: 'Sorry, but you don't have the necessary accoutrements" " Environment and Planning A 32581 - 598

Antill J K, Cotton S, 1988, "Factors affecting the division of labour in households" Sex Roles $18531-553$

Arentze T A, Timmermans H J P, 2000 ALBATROSS: A Learning-based Transportation Oriented Simulation System (EIRASS, Eindhoven)

Axhausen K W, Simma A, Golob T, 2001, "Precommitment and usage: season tickets, cars, and travel”, in Transport Planning, Logistics, and Spatial Mismatch Ed. D Pitfield (Pion, London) pp $101-110$

Bhat C R, Pendyala R M, 2005, "Modeling intra-household interactions and group decisionmaking" Transportation $32443-448$

Boarnet M G, Crane R, 2001 Travel by Design: The Influence of Urban Form on Travel (Oxford University Press, Oxford)

Burns L D, 1979 Transportation, Temporal and Spatial Components of Accessibility (Lexington Books, Lanham, MD)

Dowling R, 2000, "Cultures of mothering and car use in suburban Sydney: a preliminary investigation" Geoforum 31345 - 353

Esping-Andersen G, 1999 Social Foundations of Postindustrial Economies (Oxford University Press, Oxford)

Ettema D F, Schwanen T, Timmermans H J P, 2007, "The effect of location, mobility and sociodemographic factors on task and time allocation in households" Transportation 34 89- 105 
Gliebe J P, Koppelman F S, 2002, "A model of joint activity participation between household members" Transportation $3049-72$

Golob T F, 2003, "Structural equation modeling for travel behavior research" Transportation Research B 37 1-25

Hägerstrand T, 1970, "What about people in regional science?" Regional Science Association Papers 24 7-21

Hanson S, 1982, "The determinants of daily travel-activity patterns: relative location and sociodemographic factors" Urban Geography 3 179-202

Hanson S, Hanson P, 1981, “The impact of married women's employment on household travel patterns: a Swedish example" Transportation $10165-183$

Hanson S, Pratt G, 1995 Gender, Work and Space (Routledge, London)

Huber J, Spitze G, 1983 Sex Stratification: Children, Housework and Jobs (Academic Press, New York)

Jöreskog K G, 2001, "Analysis of ordinal variables 2: cross-sectional data", available at http://www.sscicentral.com/lisrel/ord2.pdf

Kitamura R, 1983, "Serve passenger trips as a determinant of travel behavior", in Recent Advances in Travel Demand Analysis Eds S Carpenter, P Jones (Gower, Aldershot, Hants) pp 137- 162

Knijn T, 2004, "Challenges and risks of individualisation in the Netherlands" Social Policy and Society $357-65$

Krygsman S, 2004 Activity and Travel Choice(s) in Multimodal Public Transport Systems Faculty of Geosciences, Utrecht University

Kwan M-P, 1999, "Gender, the home-work link and space-time patterns of nonemployment activities" Economic Geography 76370 - 394

Kwan M-P, 2000, "Gender differences in space-time constraints" Area 32 145-156

Kwan M-P, Weber J, 2003, "Individual accessibility revisited: implications for geographical analysis in the twenty-first century" Geographical Analysis $35341-353$

Massey D, 1995 Space, Place, and Gender (University of Minnesota Press, Minneapolis, MN)

Misra R, Bhat C, 2001, "Activity-travel patterns of non-workers in the San Francisco Bay Area: An exploratory analysis" Transportation Research Record 171843 - 51

Morris L, 1990 The Workings of the Household (Polity Press, Cambridge)

Ng C F, 2003, "Satisfying shoppers' psychological needs: from public market to cyber-mall" Journal of Environmental Psychology 23439 - 455

Nishii K, Kondo K, 1992, "Trip linkages of urban railway commuters under time-space constraints: Some empirical observations" Transportation Research B $2633-44$

Pas E I, 1984, "The effect of selected sociodemographic characteristics on daily travel-activity behavior" Environment and Planning A 16571 - 581

Pinch S, Storey A, 1992, "Who does what, where?: a household survey of domestic labour in Southampton" Area 24 - 12

Presser H B, 1994, "Employment schedules among dual-earner spouses and the division of household labor by gender" American Sociological Review 94348 - 364

Presser H B, 2003 Working in a 24/7 Economy: Challenges for American Families (Russell Sage Foundation, New York)

Srinivasan S, Bhat C R, 2005, "Modeling household interactions in daily in-home and out-of-home maintenance activity participation" Transportation $32523-544$

Timmermans H J P, Dijst M, Maat K, Kapoen L L, 1998 AMADEUS Research Program (Eindhoven University of Technology, Eindhoven)

Van der Valk J, 2005, "Arbeidsdeelname van paren" [Couples' labour force participation] SociaalEconomische Trends $3^{\mathrm{e}}$ kwartaal $27-31$

Verburg T, Dijst M, Schwanen T, 2005 Leef-en Mobiliteitstijlen Stedenbaan [Life and Mobility Styles Stedenbaan] Faculty of Geosciences, Utrecht University 
Conditions of use. This article may be downloaded from the E\&P website for personal research by members of subscribing organisations. This PDF may not be placed on any website (or other online distribution system) without permission of the publisher. 